\section{Morphological Evidence that High Density Lipoproteins Are Not Internalized by Steroid-producing Cells during In Situ Organ Perfusion}

\author{
Eve Reaven, Yii-Der Ida Chen, Marjorie Spicher, \\ and Salman Azhar \\ Department of Medicine, Stanford University School of Medicine, \\ and Geriatric Research, Education and Clinical Center, Veterans \\ Administration Medical Center, Palo Alto, California 94304
}

A lipoproteins (HDL) can rat cell systems, questions still arise as to how HDL are processed by cells. In particular, it is not yet clear whether HDL are internalized by a pathway similar to that used for low density lipoproteins. This issue was examined in the present study using the luteinized ovaries of hormone-primed immature rats in an in situ perfusion system. Ovaries were perfused for 2-120 min with ${ }^{125} \mathrm{I}$-labeled human or rat $\mathrm{HDL}$ and processed for autoradiographic studies at the light and electron microscopic level, or homogenized and used for isolation of subcellular membranes. The results show that the luteal cells of this tissue bind both human and rat HDL with great specificity. Moreover, the intact HDL particle does not appear to be internalized by the luteal cell during the period of perfusion: i.e., the protein moiety of the labeled HDL remains associated with the plasma membrane at all times. Evidence from the autoradiographs suggest, however, that with time, an increasing proportion of the plasma membrane-bound protein is associated with inverted microvilli, which are embedded within the cytoplasm and make close contact with structures of the interior of the cell. We speculate that HDL-cholesterol may be transferred at such sites.

\section{Introduction}

Although it appears that rat steroidogenic tissues receive a major supply of exogenous cholesterol from circulating high density lipoprotein (HDL) particles (see reference 1 for review),

\footnotetext{
Address correspondence and reprint requests to Dr. Reaven. Received for publication 23 January 1984 and in revised form 8 May 1984.
}

The Journal of Clinical Investigation, Inc. Volume 74, October 1984, 1384-1397 precisely how (and where) the transfer of cholesterol occurs is not known. In an excellent review of the subject, Gwynne and Strauss III (1) concluded that while the mechanism of uptake of HDL cholesterol is uncertain, it does not seem to require lysosomal apolipoprotein degradation to be effective, and as such, differs from the manner in which low density lipoproteins (LDL) cholesterol is processed. There is, in fact, no consensus on whether the intact HDL particle (like the LDL particle) even enters the cell during delivery of its cholesterol. It is of interest, however, that Paavola and Strauss III (2), in a recently published autoradiographic study of perfused luteinized ovaries, report that, with time, increasing amounts (up to $65 \%$ ) of luteal cell (LC) ${ }^{1}$ bound ${ }^{125}$ I-labeled HDL are actually internalized. However, the exposed grains in the interior of the cell do not appear to be associated with specific organelles, and the authors are cautious in implying that the interiorized HDL are actually associated with steroidogenesis.

The current study, which was in progress at the time the above report appeared, uses a similar animal model, and basically the same technology, but comes to a somewhat different conclusion. We show that essentially all $(\sim 90 \%)$ of the exposed grains associated with luteal cells always remain on the plasma membrane. However, with increasing time of perfusion, it appears that a proportion of these grains move to unique regions of the membrane that are in close physical contact with the cytoplasm of the cell. We speculate that HDLcholesterol may be transferred at such sites.

\section{Methods}

Materials. Purified human chorionic gonadotropin (hCG CR-121, secretory potency $13,450 \mathrm{IU} / \mathrm{mg}$ ) was kindly provided by Dr. R. E. Canfield, through the Center for Population Research of the National

1. Abbreviations used in this paper: 4-APP, 4-aminopyrazole [3,4]-d pyrimidine; apo A-I, apolipoprotein A-I; ARGs, autoradiographic studies; CV, coated vesicles; EC, endothelial-lining cells; EM, electron microscope; EM-ARGs, electron microscope ARGs; h, human; hCG, human chorionic gonadotropin; LM-ARG, light microscope autoradiogram; LC, luteal cell; MV, microvilli; $r$, rat. 
Institute of Child Health and Human Development, Bethesda, MD. The following chemicals were supplied by Sigma Chemical Co., St. Louis, MO: pregnant mare serum gonadotropin, hCG, progesterone, and bovine serum albumin (BSA). $\left[1,2,6,7-{ }^{3} \mathrm{H}\right]$ Progesterone $(97 \mathrm{Ci}$ / mmol) and carrier free $\left[{ }^{125} \mathrm{I}\right] \mathrm{NaI}$ were purchased from Amersham Corp., Arlington Heights, IL. Apolipoprotein A-I (apo A-I) was purified from human (h)-HDL by a slightly modified procedure of Edelstein et al. (3): i.e., apoproteins were chromatographed two times using Sephacryl S-200 columns (Pharmacia Fine Chemicals, Piscataway, NJ).

Animal protocol. Superovulated rats were prepared as previously described (4). In brief, 26-d-old female Sprague-Dawley rats were primed by subcutaneous injections of $50 \mathrm{IU}$ pregnant mare serum gonadotropin followed $56 \mathrm{~h}$ later by $25 \mathrm{IU}$ of hCG (5). The rats were used for experiments 6-7 d after the final hCG injection. Once the animals were anesthetized (sodium thiamylol, $60 \mathrm{mg} / \mathrm{kg}$ body weight), preparation for perfusion took no more than 3-4 min. A vertical incision was made through the abdominal wall, renal and femoral arteries were ligated, the descending aorta at the level of the superior mesenteric artery was exposed, cannulated, and flushed with oxygenated medium 199 (containing $50 \mu \mathrm{g} / \mathrm{ml}$ gentamicin); immediately thereafter the thorax was opened and the vessels severed to permit drainage of the perfusate into the chest. (When desired, perfusate could be collected from the inferior vena cava at this point of entry into the liver.) Through the use of more than one perfusion pump (Harvard compact infusion pump, model 975, Harvard Apparatus Co., Inc., S. Natick, MA) and 3-way stop cocks, several different solutions could be conveniently perfused in sequence. Temperature of the perfusate was maintained between 33 and $35^{\circ} \mathrm{C}$, and perfusate flow was usually at $2.2 \mathrm{ml} / \mathrm{min}$ (flow was reduced to 0.6 or $1.1 \mathrm{ml} / \mathrm{min}$ for perfusions lasting $>1 \mathrm{~h}$ ). The surgical preparation of the animal was considered acceptable when the ovaries blanced completely $\sim 30 \mathrm{~s}$ from the onset of perfusate flow.

After this initial flushing period, the ovaries were perfused for 2 120 min with medium 199 that contained ${ }^{125}$ I-labeled $h$ or rat (r)HDL (the specific activity of the protein varied and is indicated in particular experiments). In every case, this perfusion was followed by a brief $(2 \mathrm{~min}$ ) wash with medium 199. The ovaries were then further perfused with fixative ( $2 \%$ glutaraldehyde in $0.1 \mathrm{M}$ cacodylate buffer, pH 7.2) and processed for autoradiographic studies (ARGs) at the light and electron microscopic level, or immediately excised, cleaned of extraneous tissues, and monitored for total uptake of radioactivity by the use of a gamma counter (LKB, model 1275 Minigamma). Some radioactive ovaries were excised (without fixation), counted for radioactivity, homogenized, and used for isolation of subcellular membranes.

Preparation of autoradiographs (ARGs). When ovaries were to be prepared for ARGs, each animal received $45 \mu \mathrm{Ci} / \mathrm{ml}{ }^{125} \mathrm{I}-\mathrm{h}$ - or r-HDL plus unlabeled $\mathrm{h}$ - or $\mathrm{r}$-HDL $(200 \mu \mathrm{g}$ protein/ml). After perfusion fixation with glutaraldehyde, the ovaries were yellow in color and hardened in texture. After removal of extraneous tissues, the ovaries were monitored (as stated above) for total radioactivity, diced into tiny pieces, and fixed for an additional $3-4 \mathrm{~h}$ in glutaraldehyde. Subsequently the tissue was washed overnight in three changes of $0.2 \mathrm{M}$ cacodylate buffer, post-fixed in $1 \%$ osmium, stained en bloc with uranyl acetate $(2 \%, \mathrm{pH} 5.5)$, dehydrated in alcohols and propylene oxide, and pieces of tissue of similar size were embedded in epon-araldite plastic. Before sectioning, blocks of tissue were again monitored for radioactivity and the blocks with the highest levels of radioactivity were thick and thin sectioned. Light microscope autoradiography (LM-ARG) was performed using Kodak NTB-2 emulsion, Eastman Kodak Co., Rochester, NY.
Sections were exposed at $4^{\circ} \mathrm{C}$ for $2-8 \mathrm{~d}$ before development. For electron microscope (EM) ARGs, thin (silver-grey) sections were placed on parlodion-coated nickel grids ( 400 mesh), stained with lead citrate and uranyl acetate, and coated with carbon and Ilford L-4 emulsion by a standard 'loop' technique (6): test samples of the gelled emulsion were considered suitable when the emulsion crystals lay in a closely packed monolayer as viewed by electron microscopy. Grids were exposed for 2-8 wk before development with Microdal X (undiluted) at $20^{\circ} \mathrm{C}$ for $3.5 \mathrm{~min}$. Controls for positive and negative chemography were included in initial experiments and found to be negative.

Quantitative measurements on EM autoradiographs. Morphological quantitation in this study was limited to two questions: $(a)$ was the intact HDL particle with its radioactive protein coat internalized by luteal cells; and $(b)$ was there measurable translocation of radioactivity as the length of time of HDL perfusion increased?

Assessment of the first question was relatively simple. Different sets of ARGs from each sample were developed at weekly intervals until one set proved to have sufficient grains for quantification. At this point, 10 nucleated cells (chosen at random) of each of three blocks per sample were photographed at a low magnification $(\times 4,000)$ so as to include an image of the entire cell: such micrographs were printed on $11 \times 14$ sheets of paper. Each exposed grain that was determined to be associated with the LC in question was delineated with a tightfitting circle: the number of grains varied from $\sim 15-30 /$ cell. During quantitation, the number of exposed grains having any part of their circle touching any part of the LC plasma membrane were counted and compared with the number of encircled grains within the cell not touching the plasma membrane. It should be noted that since the large majority of grains appeared to be associated with the plasma membrane, it was not necessary to correct the measurements for spread of radioactivity (7), and, as such, the percentage of grains actually associated with the plasma membrane was somewhat underestimated.

The second type of quantitation that was done on these same ARGs was more difficult to design. As will be detailed below, the surface of luteal cells is extremely complex, with microvillus-like fingers protruding beyond the cell into the subendothelial cell space, as well as into the LC itself, forming cavities bounded by two opposing lengths of plasma membrane. As these 'cavities' appeared to contain an unusually large number of exposed grains, it seemed reasonable to ask whether the actual percentage of plasma membrane grains associated with the cavities (relative to plasma membrane grains associated with the outside of the cell) changed with time of perfusion of HDL. To cover all situations, a cavity was defined as a region of the cell surface separated from the cytoplasm of the cell by a double plasma membrane. During quantitation, the double plasma membranes of all such cavities of the low-magnification micrographs were identified (with the aid of a magnifying lamp) and marked with a colored pencil; double blind techniques were used to avoid bias. Once marked, the percentage of grains associated with such cavities was assessed by counting the number of encircled grains touching the marked areas, and by comparing this value with the total number of encircled grains that touched the plasma membrane.

Preparation of subcellular fractions for biochemical and morphological analysis. Lutenized ovaries were perfused with or without ${ }^{125} \mathrm{I}$-hHDL $(1 \mu \mathrm{Ci} / \mathrm{ml}$ plus $200 \mu \mathrm{g} / \mathrm{ml}$ unlabeled hHDL), homogenized, and processed for sucrose density gradient centrifugation as shown in Fig. 1. A total of 38 sequential $(1 \mathrm{ml})$ fractions were obtained from the top of the gradients with the aid of a 1-ml automatic pipetter (Pipetman $P-1(0)$ ()). Radioactivity was used to monitor the intracellular translo- 
FLOW DIAGRAM OF THE PROCEDURE FOR ISOLATING MEMBRANE FRACTIONS FROM LUTEINIZED OVARIES

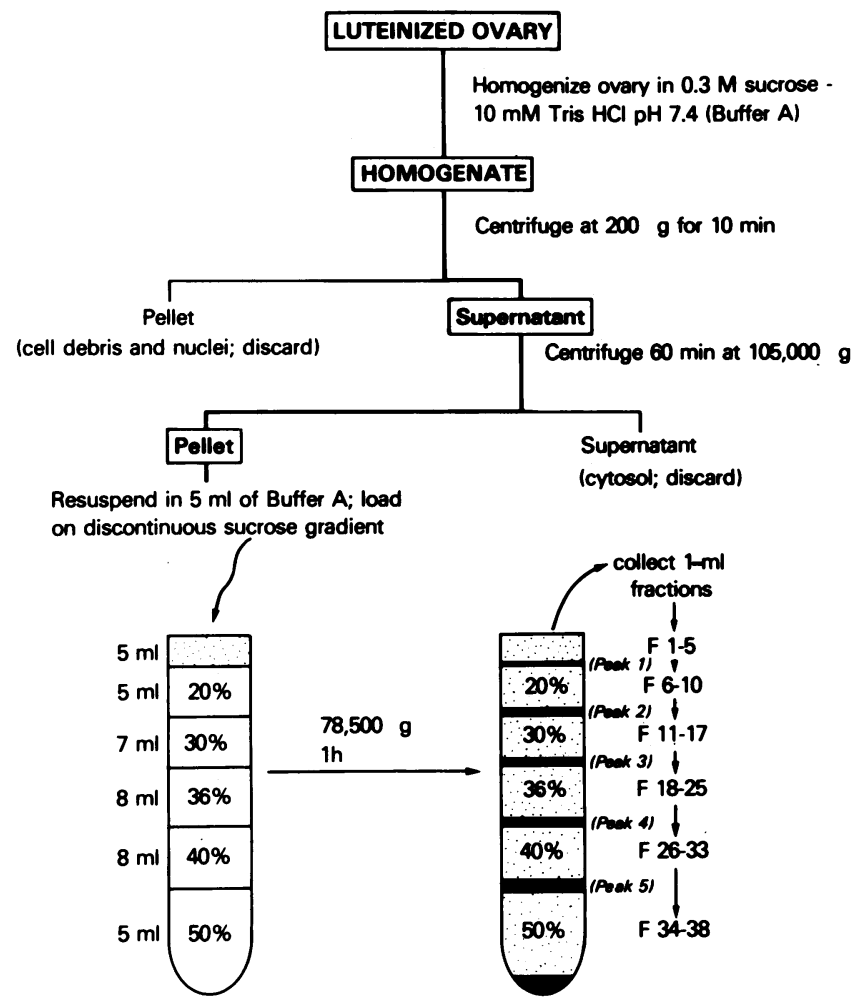

Figure 1. Procedure for isolating membrane fractions from luteinized ovaries. After perfusion with ${ }^{125} \mathrm{I}-\mathrm{h}-\mathrm{HDL}$, all fractions were analyzed for radioactivity and for marker enzyme activity.

cation of label with time, and enzyme markers and electron microscopy was used to identify the composition of the fractions. Each marker (i.e., 5'nucleotidase [plasma membranes]; NADPH-cytochromc $\mathrm{C}$ reductase [microsomes]; succinic-INT-dehydrogenase [mitochondria]; galactosyltransferase [Golgi]; and $\beta$-glucuronidase and acid phosphatase [lysosomes]) were assessed for all $38(1 \mathrm{ml})$ fractions that were obtained from the sucrose gradients. Enzyme assays were carried out as previously described from this laboratory (8).

The plasma membrane content of individual fractions was further assessed by the ability of the membranes to bind the surface active hormone, hCG. For this purpose, 1-ml aliquots of sucrose gradient fractions of non- ${ }^{125}$ I HDL-labeled ovaries were incubated in vitro with ${ }^{125} \mathrm{I}$-hCG $\left(2.5-3.5 \times 10^{5} \mathrm{cpm}\right.$ of ${ }^{125} \mathrm{I}-\mathrm{hCG}, 0.1 \%$ BSA in $0.3 \mathrm{ml}$ phosphate-buffered saline) as previously done in this laboratory (9).

In addition, gradient-separated membranes that were associated with the highest peaks of ${ }^{125}$ I-HDL radioactivity were recentrifuged $(50,000 \mathrm{~g}$ for $30 \mathrm{~min})$ to remove sucrose, resuspended in small volumes of $0.25 \mathrm{M}$ sucrose, fixed with $1 \%$ glutaraldehyde (in $0.1 \mathrm{M}$ cacodylate) for $10 \mathrm{~min}$, and repelleted for $30-60 \mathrm{~min}$ at $100,000 \mathrm{~g}$ using a fixed angle rotor (Beckman Type 35 rotor, Beckman Instruments Inc., Palo
Alto, CA). The pelleted material was loosely precipitated along the length of the tube and could be fixed and embedded as a thin shell of material, which permitted thin sectioning through its entire thickness. Electron microscope ARGs (EM-ARGs) were prepared from such preparations after the techniques outlined above and exposed for $3 \mathrm{mo}$.

Finally, since mitochondria did not remain structurally intact during sucrose gradient centrifugation, an additional procedure that involved the use of mannitol for mitochondria protection and less intense g-forces during separation (10) was also used to isolate mitochondria: mitochondria prepared in this fashion are structurally intact, but contaminated with other subcellular membranes. EM-ARGs were prepared from such preparations as outlined above and exposed for 2-3 mo.

To assess which structures in the pelleted mitochondrial material were associated with radioactivity, 10 photographs of one pellet of each of three experiments (i.e., one mitochondrial/lysosome pellet and two special mitochondrial pellets from 50 min ${ }^{125}$ I-HDL perfusion experiments) were obtained at $\times 16,000$. The only criterion used for selecting the sites to be photographed was that at least three exposed grains would have to appear in each photograph. This kind of selection was necessary to obtain sufficient grains for counting in the pelleted samples that showed low radioactivity. The volume density of mitochondria, lysosomes, unidentified smooth surfaced membranes, or vesicles with striated double membranes (see Results for description) was separately assessed in each micrograph using standard techniques as described by Weibel (11) and previously used in this laboratory (see reference 12). The number of exposed grains associated with each category of structures in the same picture was subsequently assessed. If a specific grain touched two different structures, each received onehalf a point; if a specific grain touched more than two structures, the two structures most clearly 'hit' were counted while the others were ignored (insofar as the pelleted material was not heavily packed, this latter situation occurred only rarely). The proportion of total exposed grains that were associated with each category of structures in each micrograph was assessed in relation to the content (percentage) of that structure in the micrograph. Thus, if the ratio of percentage of grains to percentage of structure was equal to (or less than) unity, the structures were not considered to be specifically labeled; in contrast, if the percentage of grains related to a specific category of structures was greater than unity, these structures were considered specifically labeled.

Miscellaneous techniques. Rat HDL ( $d=1.090-1.215)$ was isolated from pooled serum from male retired breeder rats. Human HDL (i.e., $\mathrm{HDL}_{3}, d=1.125-1.215$ ) was isolated from fresh plasma. HDL preparation and purification was carried out as previously described from this laboratory (9). HDL iodination was carried out using the iodine monochloride method of McFarlane (13) as previously described (14), with the exception that a modification was made to prepare labeled HDL with higher specific activity (500-1,000 cpm/ng HDL protein).

To test the ability of the radiolabeled HDL to promote progesterone production, aliquots of LC (1-2 $2 \times 10^{6}$ cells) prepared as described previously (9) were incubated in polyethylene tubes in a final volume of $1 \mathrm{ml}$ of medium 199 that contained $0.2 \% \mathrm{BSA}$, and in the presence or absence of hCG $(10 \mathrm{ng} / \mathrm{ml})$ or ${ }^{125} \mathrm{I}-\mathrm{h}-\mathrm{HDL}(800 \mu \mathrm{g}$ protein $/ \mathrm{ml})$. After incubation at $37^{\circ} \mathrm{C}$ for $4 \mathrm{~h}$ in the presence of $\mathrm{O}_{2} / \mathrm{CO}_{2}(95: 5 \mathrm{vol} /$ vol), the samples were processed for progesterone quantitation by radioimmunoassay as described by Abraham et al. (15).

To test the response of the luteinized ovary to saturating levels of $\mathrm{HDL}$, ovaries were perfused for $1 \mathrm{~h}(0.6 \mathrm{ml} / \mathrm{min})$ with unlabeled $\mathrm{h}$ HDL (500 $\mu \mathrm{g}$ protein/ml) or with medium 199 alone; effluent was 
collected using a Gilson automatic fraction collector (model FC-80K, Gilson Medical Instruments Inc., Middleton, WI). Each sample was extracted and assayed for progesterone by radioimmunoassay as described by Abraham et al. (15).

Two procedures were used to determine if the radioactivity of the subcellular fractions after density gradient separation remained associated with HDL-protein. In the first, mitochondrial/lysosomal fractions were precipitated with TCA, centrifuged, and the remaining radioactivity of the supernatant was assessed. In the second procedure, $20 \mu \mathrm{g}$ protein from purified ${ }^{125} \mathrm{I}-\mathrm{h}-\mathrm{HDL}$ or from the particulate fraction of ${ }^{125} \mathrm{I}-\mathrm{h}$ HDL-perfused ovaries $(1 \mu \mathrm{Ci} / \mathrm{ml}$ plus $200 \mu \mathrm{g}$ unlabeled HDL per milliliter) were loaded on $12 \%$ SDS polyacrylamide gels and subjected to electrophoresis (16). Protein bands were identified with molecular weight standards and purified apo A-I, and radioactive proteins in the samples were identified by radioautography.

\section{Results}

Uptake of radioactivity in perfused, intact ovaries Effect of increasing concentration and time on ${ }^{125}$ I-HDL uptake. When the intact ovaries were perfused with ${ }^{125} \mathrm{I}-\mathrm{h}-\mathrm{HDL}(2$ $\times 10^{6} \mathrm{cpm} / \mathrm{ml}$ ) plus increasing concentrations of unlabeled HDL for $30 \mathrm{~min}$, HDL saturation occurred with $\sim 200 \mu \mathrm{g}$ $\mathrm{HDL} / \mathrm{ml}$ (Fig. $2 \mathrm{~A}$ ). Using this saturating concentration of
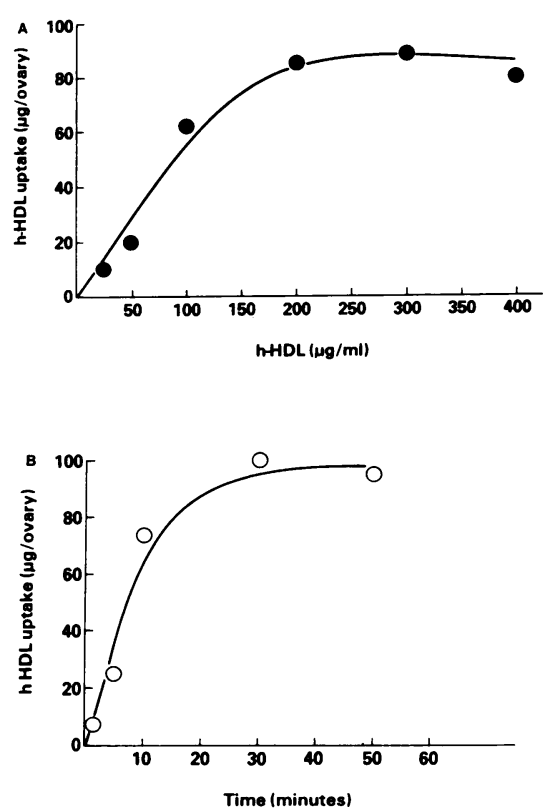

Figure 2. Concentration- and time-dependent uptake of h-HDL by luteinized ovaries. Ovaries were continuously perfused with ${ }^{125} \mathrm{I}-\mathrm{h}$ HDL $(1 \mu \mathrm{C} / \mathrm{ml} ; 0.5 \mu \mathrm{C} / \mathrm{ng})$ plus indicated concentrations of unlabeled $\mathrm{HDL}$ for $30 \mathrm{~min}(A)$, or with ${ }^{125} \mathrm{I}-\mathrm{h}-\mathrm{HDL}(1 \mu \mathrm{C} / \mathrm{ml} ; 0.5 \mu \mathrm{C} / \mathrm{ng})$ plus unlabeled $\mathrm{h}$-HDL $(200 \mu \mathrm{g} / \mathrm{ml})$ for varying time periods $(B)$. Uptake is expressed as microgram HDL protein bound $\left({ }^{125} \mathrm{I}-\mathrm{HDL}\right.$ plus unlabeled HDL). Each point represents the mean uptake of two ovaries from each of two separate perfusions.

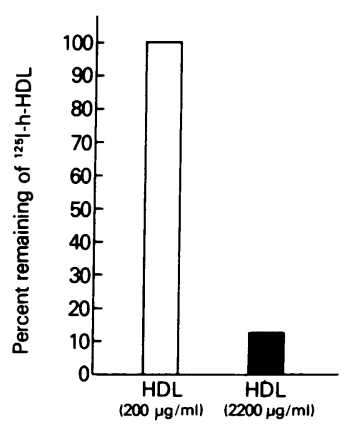

Figure 3. Percentage of displacement of ${ }^{125} \mathrm{I}-\mathrm{h}$-HDL uptake by unlabeled HDL in perfused luteinized ovaries. Ovaries were continuously perfused with ${ }^{125} \mathrm{I}-\mathrm{h}-\mathrm{HDL}(1 \mu \mathrm{C} / \mathrm{ml})$ plus 200 or $2,000 \mu \mathrm{g} / \mathrm{ml}$ unlabeled HDL for 30 min. Each bar represents mean data from two ovaries of each of two separate perfusions.

HDL it was possible to define a time course for HDL uptake by the luteinized ovaries. Fig. $2 \mathrm{~B}$ indicates that maximal HDL uptake occurs after $\sim 30 \mathrm{~min}$ of perfusion.

Specificity of uptake of ${ }^{125} I-H D L$. Fig. 3 demonstrates that a 10-fold increase in unlabeled h-HDL displaces $80-90 \%$ of the total radioactivity taken up by the perfused ovaries. Additional evidence for specificity came from LM-ARGs, as illustrated by Fig. 4, which shows that the exposed grains are primarily associated with the LC of the tissue and that vascular EC, undifferentiated LC, and Graafian follicles remain essentially unlabeled.

Lipoprotein-stimulated progesterone secretion. Fig. 5 indicates that perfusion of luteinized ovaries with saturating levels of $\mathrm{h}$-HDL results in a dramatic increase in progesterone secretion. Overall, this response represented a 10 -fold increase over the progesterone response of ovaries that were perfused with HDL-free medium. Table I shows that the radiolabeled HDL used for the various experiments of this study are as effective as unlabeled HDL in promoting progesterone synthesis in isolated cell systems.

Localization of radioactivity in intact tissue: information from EM-ARGs. Examination of autoradiograms of the luteinized ovaries from both early (2-3 min) or later (50 and 120 min) time points after perfusion of either ${ }^{125} \mathrm{I}-\mathrm{h}$ - or $\mathrm{r}-\mathrm{HDL}$ showed exposed grains to be almost exclusively associated with the plasma membranes of LC (Fig. 6). In this tissue, LC are often arranged in cords, with usually two membrane faces of each cell (with microvilli (MV)-like projections) being in direct contact with adjacent LC, while the remaining surfaces of the cell (bordered by an intricate array of MV) are enclosed in a space (luteal cell space) that is formed by the basement membrane surface of EC on one side and the surface of the LC on the other. These features of the luteal cell (the MV, MV space, EC, and sinusoidal space) are clearly seen in Fig. 6. It is of interest, too, that a delicately thin basement membrane (see arrowheads in Fig. 7) lies over the microvillus surface along its entire length, and it would appear that any blood-borne ligand would have to initially penetrate this membrane before coming into contact with the microvillus surface itself.

Quantitative techniques, which estimate the percentage of exposed grains that touch the plasma membrane (Table II), 


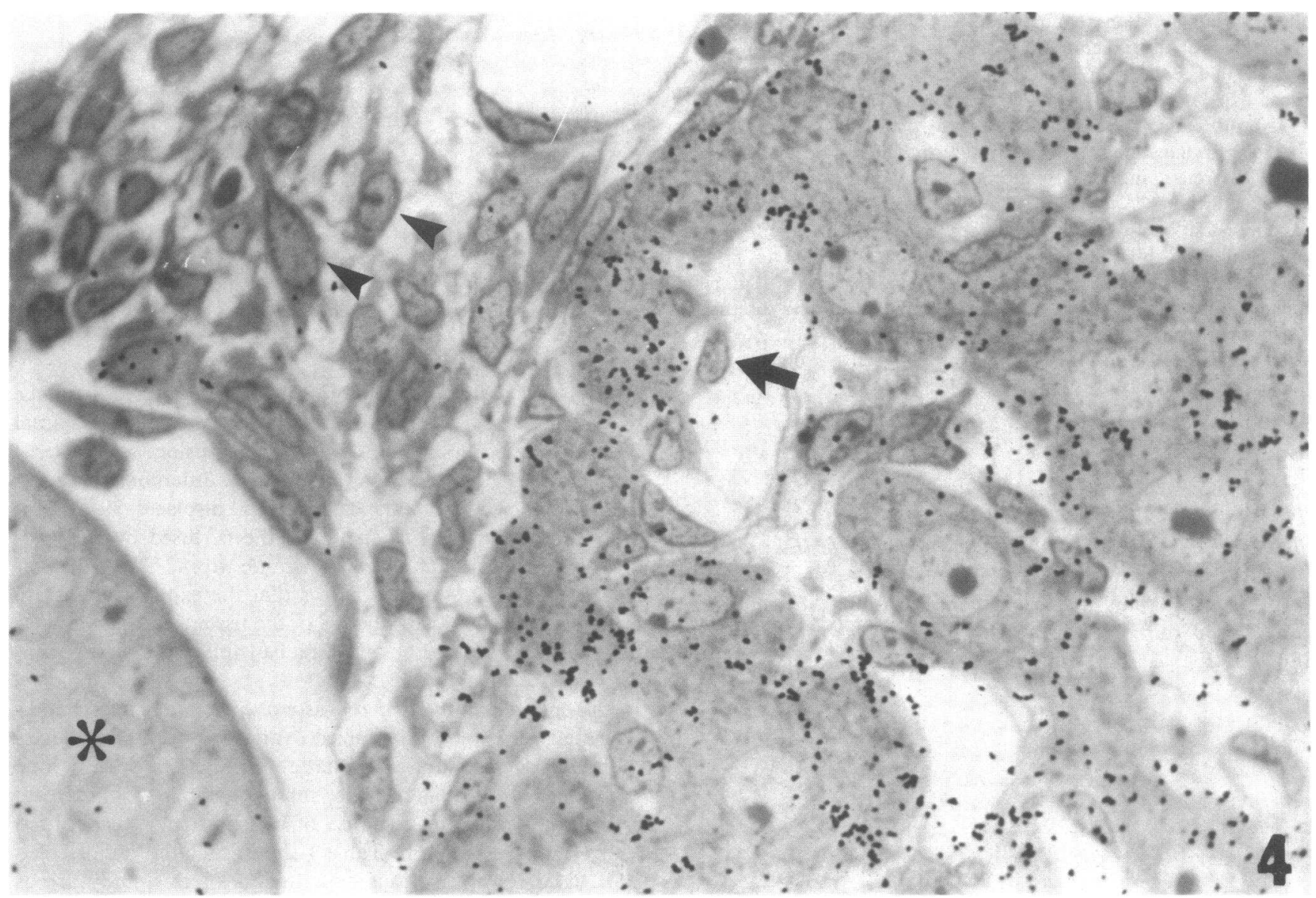

Figure 4. LM-ARG. Ovaries were continuously perfused with ${ }^{125} \mathrm{I}-\mathrm{h}$ HDL $(45 \mu \mathrm{C} / \mathrm{ml})$ and $200 \mu \mathrm{g} / \mathrm{ml}$ unlabeled HDL for $50 \mathrm{~min}$. Luteal cells (round cells with large nuclei) are highly labeled, whereas endo-

revealed that at both early and late time points, $\sim 90 \%$ of the grains were associated with some aspect of the plasma membrane. The mean values in Table II represent combined data

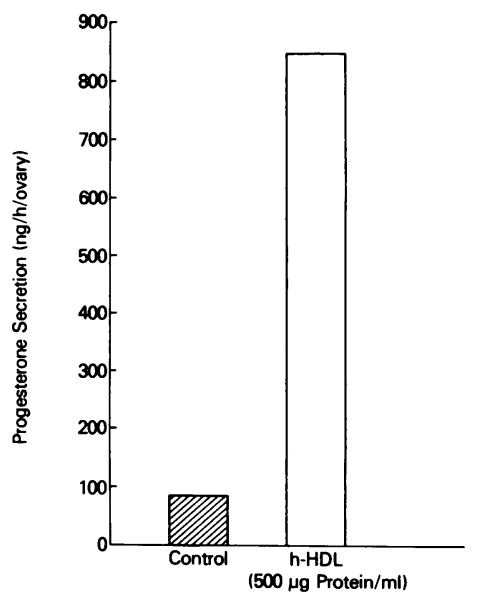

Figure 5.Progesterone response of luteinized ovaries to perfusion with HDL-free medium (control) or medium containing saturating levels $(500 \mu \mathrm{g}$ protein $/ \mathrm{ml})$ of $h$-HDL. Perfusion time equals $1 \mathrm{~h}$; perfusion rate equals $0.66 \mathrm{ml} / \mathrm{min}$. Bars represent mean $( \pm \mathrm{SEM})$ progesterone produced per hour per ovary. Data are from ovaries of two control and two HDL-perfused animals. thelial lining cells (arrows), thecal cells (arrowheads), and follicles (*) show only a few exposed grains. (Exposure time equals $7 \mathrm{~d}$ ).

from experiments in which ovaries were perfused with either ${ }^{125} \mathrm{I}-\mathrm{r}-$ or h-HDL insofar as no differences in LC grain distribution were observed with rat and human ligand.

Table I. Progesterone-promoting Activity of Iodinated HDL

\begin{tabular}{ll}
\hline Lipoprotein addition & Progesterone production \\
\hline & $n g \cdot \mu g D N A^{-1 *}$ \\
No lipoprotein & 0.9 \\
I25 I-h-HDL (800 $\mu$ g protein $/ \mathrm{ml})$ & 4.0 \\
h-HDL $(800 \mu g$ protein $/ \mathrm{ml})$ & 4.6
\end{tabular}

* Human HDL from a single preparation were either iodinated, or not, and used as substrate for progesterone synthesis by isolated luteal cells that were prepared as previously described in this laboratory (9). Additionally, when an aliquot of the same labeled ligand was used to perfuse the intact luteinized ovary, appropriate uptake of radioactivity was obtained (data not shown). 


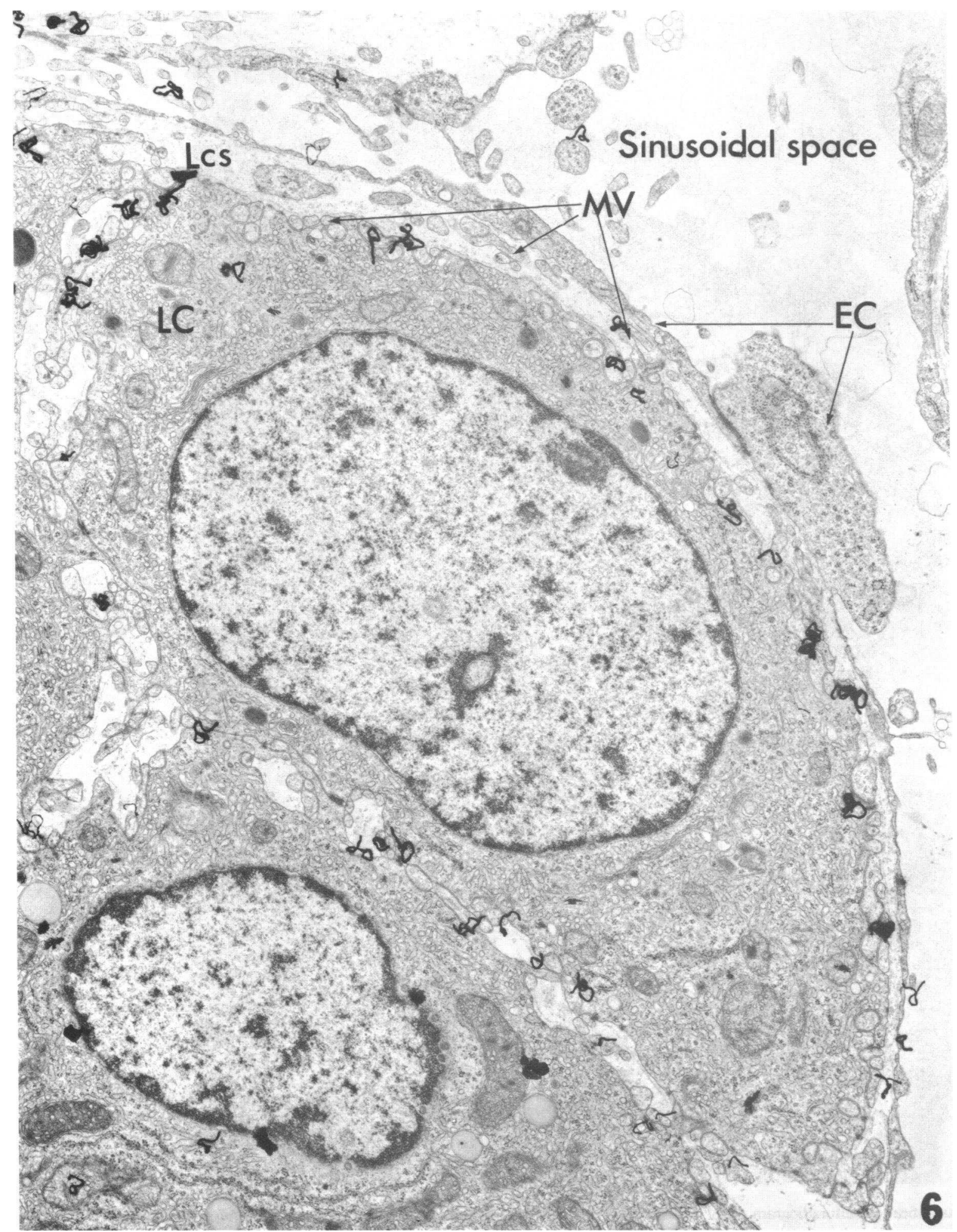

Figure 6. Typical low magnification EM-ARG of luteal cell from ovary perfused with ${ }^{125} \mathrm{I}-\mathrm{r}-\mathrm{HDL}(45 \mu \mathrm{C} / \mathrm{ml})$ for $50 \mathrm{~min}$. Exposed

grains are almost exclusively associated with the cell surface. Lcs, luteal cell space. (Exposure time equals 8 wk). $>15,000$. 


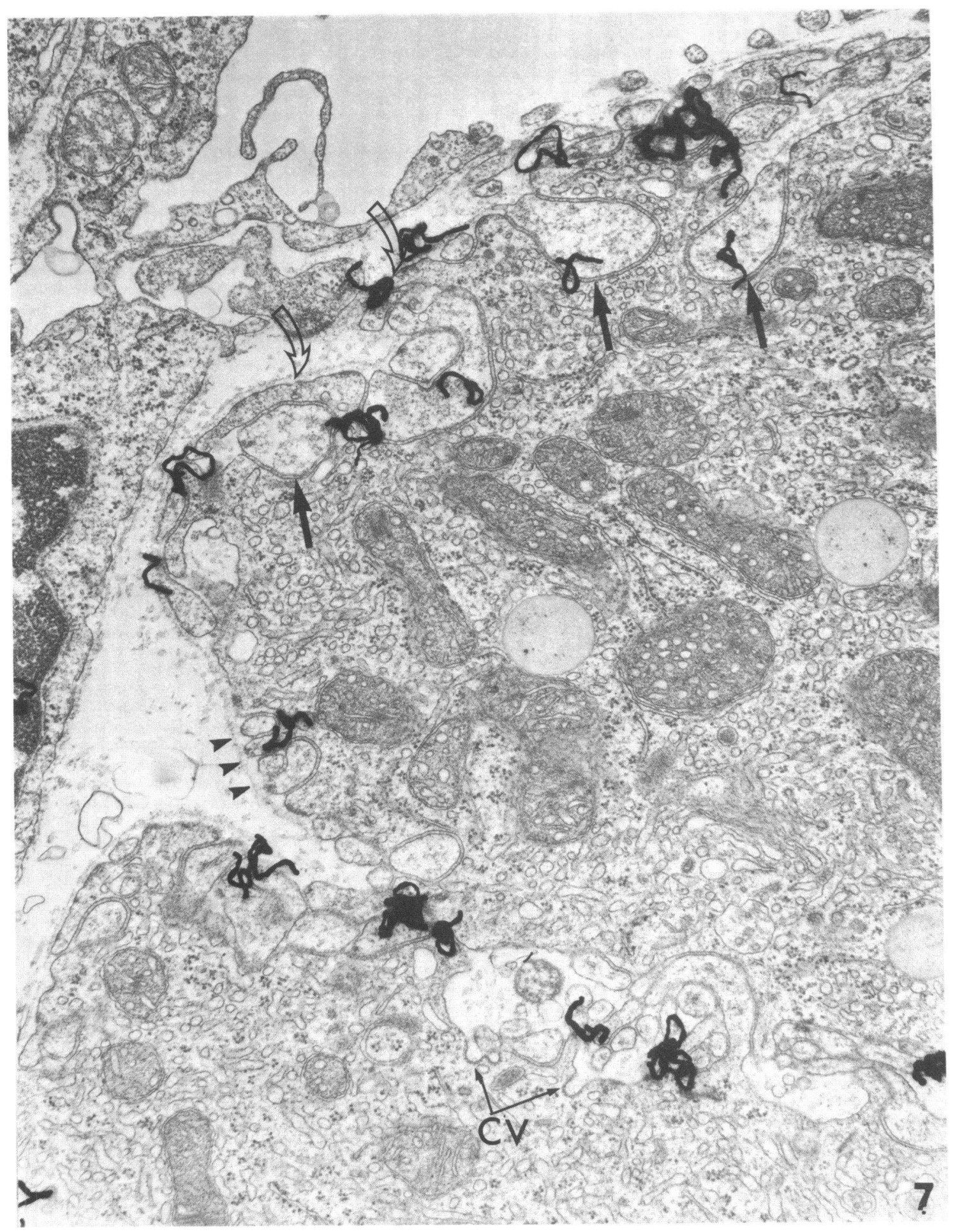

Figure 7. Higher magnification autoradiogram of the surface of a luteal cell from an ovary perfused under the same conditions as in Fig. 6. Many exposed grains are associated with regions of the plasma membrane which appear to be formed by inverted (invaginated) MV (solid arrows); open arrows indicate non-invaginated MV; CV point to coated pits; small arrowheads identify the thin basement membrane that covers the surface of luteal cells. $\times 35,000$. 
Table II. Localization of Radioactivity Associated With Luteal Cells*

\begin{tabular}{ll}
\hline $\begin{array}{l}\text { Time after } \\
\text { onset of perfusion }\end{array}$ & $\begin{array}{l}\text { Grains associated } \\
\text { with plasma membrane }\end{array}$ \\
\hline & $\%$ \\
$2-3 \mathrm{Min}$ & $96.5 \pm 0.5$ \\
$50 \mathrm{Min}$ & $92.1 \pm 0.6$ \\
$120 \mathrm{Min}$ & $88.5 \pm 1.0$ \\
\hline
\end{tabular}

* Tissues were obtained from two luteinized ovaries of each of three rats that were continuously perfused with ${ }^{125} \mathrm{I}-\mathrm{h}$ - or $\mathrm{r}-\mathrm{HDL}(45 \mu \mathrm{Ci} /$ $\mathrm{ml}$ ) plus $200 \mu \mathrm{g} / \mathrm{ml}$ of unlabeled $\mathrm{h}$ - or $\mathrm{r}-\mathrm{HDL}$ for the indicated times.

Upon closer inspection, it was clear that many of the plasma membrane-located grains were associated with infolded regions of the LC surface which physically bring the MV with their attached labels into the interior of the cell. This situation is seen in Fig. 7 (solid arrows), and at higher magnification in Figs. 8-10, where the exposed grains are clearly associated with regions of invaginated MV. These invaginated regions of MV frequently appeared swollen; that is, they appeared thicker in diameter with a looser interior fibrillar network than generally seen in non-invaginated MV (compare microvillar regions with open and solid arrows in Fig. 7). Of special interest were the fine, fibrillar connections that are generally present between the two opposing plasma membranes of the invaginated MV (see solid arrows pointing to the striated borders of the microvillar cavities in Figs. 7-9). Whether the invaginated MV fingers that were seen in a luteal cell come from adjacent luteal cells or from the same cell in which the invaginated profile is found, is not always clear, since images of both kinds can be found (see a microvillus communication between two luteal cells in Fig. 8).

Most interesting, however, is the observation that embedded

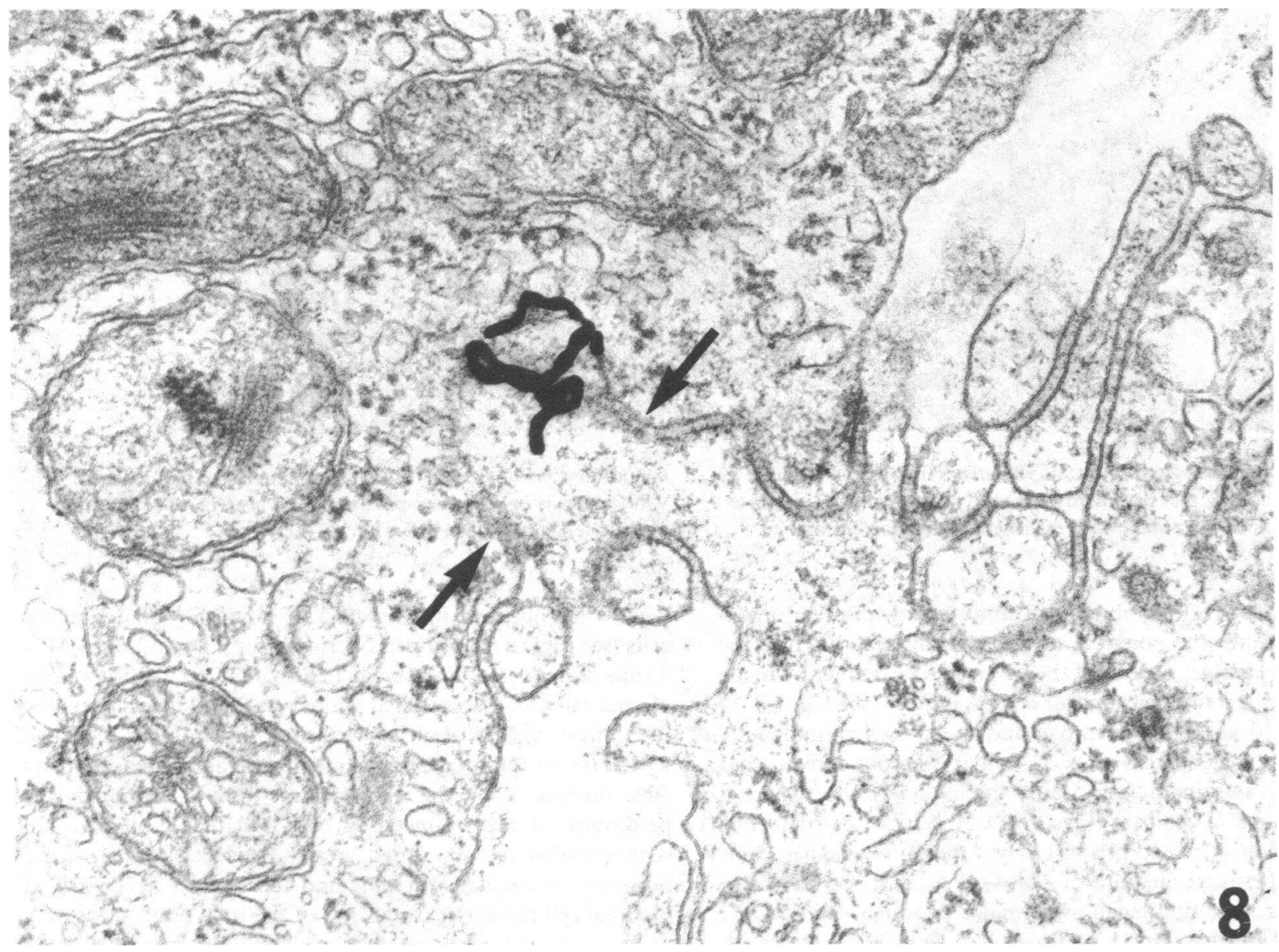

Figure 8. Higher magnification autoradiogram of LC surface from tissue perfused as in Fig. 6. This figure shows a microvillus cavity (with an exposed grain) that appears to be formed by a projection of cytoplasm from one cell embedded in a second cell (arrows). $\times 67,000$. 


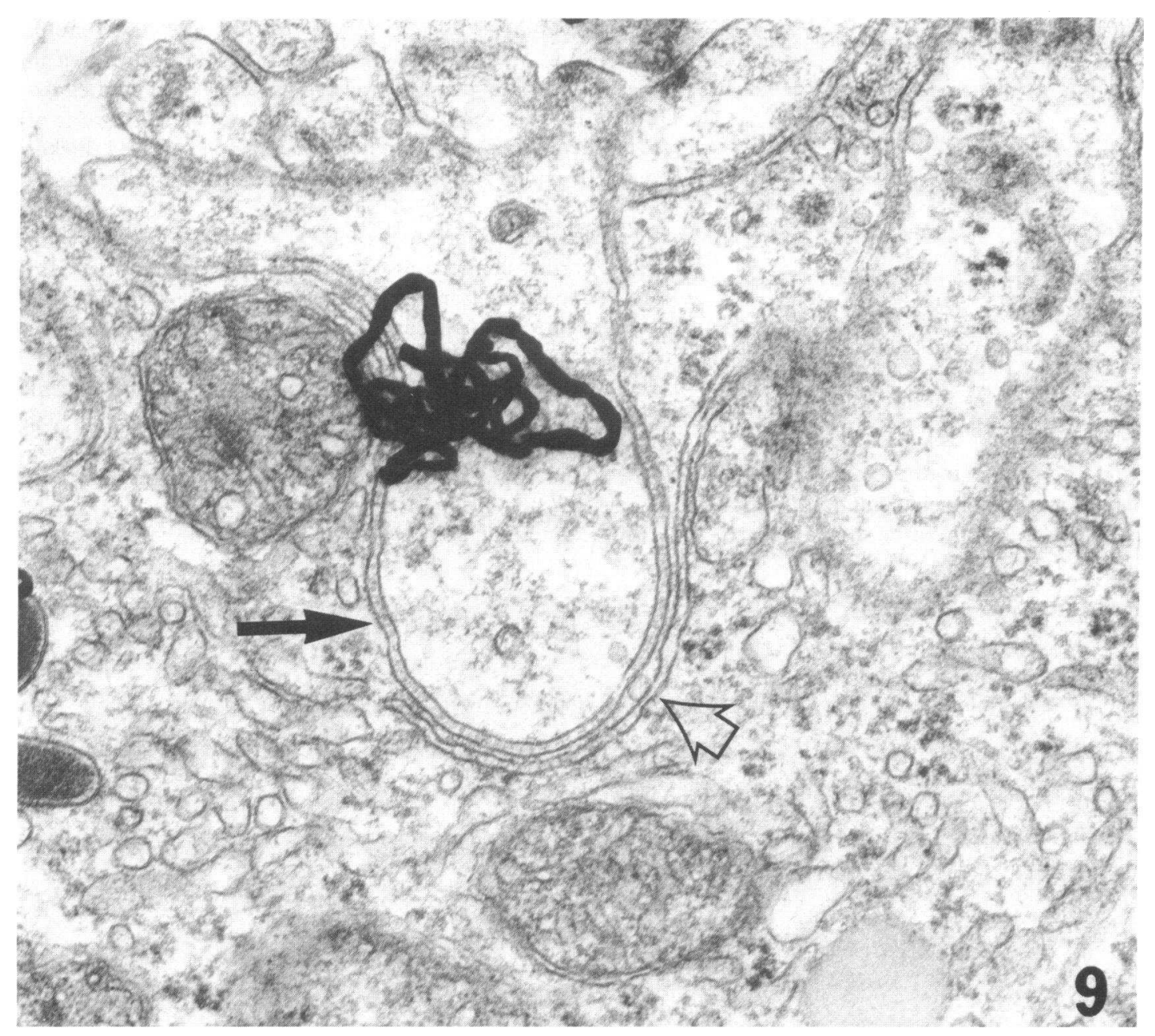

Figure 9. Autoradiogram of luteal cell surface from tissue perfused as in Fig. 6 showing that the microvillus cavity is bounded by a double layer of plasma membrane with intermembrane, filamentous-like

MV often formed membranous connections with other organelles that have the potential of transporting material into the cell. For example, regions of the inverted MV frequently made contact with coated pits and/or coated vesicles (see Fig. 7, CV; also Fig. $10 A-C$ ). It was rare to find an exposed grain directly over such coated areas (Fig. 7), but it was not rare to find exposed grains in the very same microvillus cavity where a $\mathrm{CV}$ appeared at the base (Fig. $10 \mathrm{~A}$ ). Note that the frequency and location of coated pits in LC was the same whether HDL is in the perfused medium or not. On occasion, we have also seen other structures, such as segments of rough endoplasmic reticulum (open arrow, Fig. 9), in close association with such microvillus cavities.

In an effort to determine if the labeled HDL move into the cavities as time of perfusion increases, we marked such connections (solid arrows). In this micrograph, the base of the microvillus cavity is in very close proximity to a cisterna of rough endoplasmic reticulum (open arrow). $\times 80,000$.

regions (as outlined in Methods) in randomly photographed cells (see Fig. 6) from ovaries perfused for 2 and $50 \mathrm{~min}$. After 2 min of perfusion, an average $( \pm S E M)$ of $26 \pm 3 \%$ of the total plasma membrane-associated grains was found in such cavities: in contrast, after $50 \mathrm{~min}$ of perfusion, this number increased to $40 \pm 6 \%$ of the total plasma membrane-associated grains (a $50 \%$ increase over the earliest time point). Although the percentage of the perimeter of each cell that is involved in such infolded cavities varied greatly from cell to cell, it did not seem to change with time and represented $\sim 50-60 \%$ of the total cell perimeter, regardless of the time point measured.

Localization of radioactivity: information from subcellular fractions. As indicated in Fig. 1, membranes accumulate at each sucrose gradient interface during centrifugation. Information from the various enzyme assays and electron microscopy 

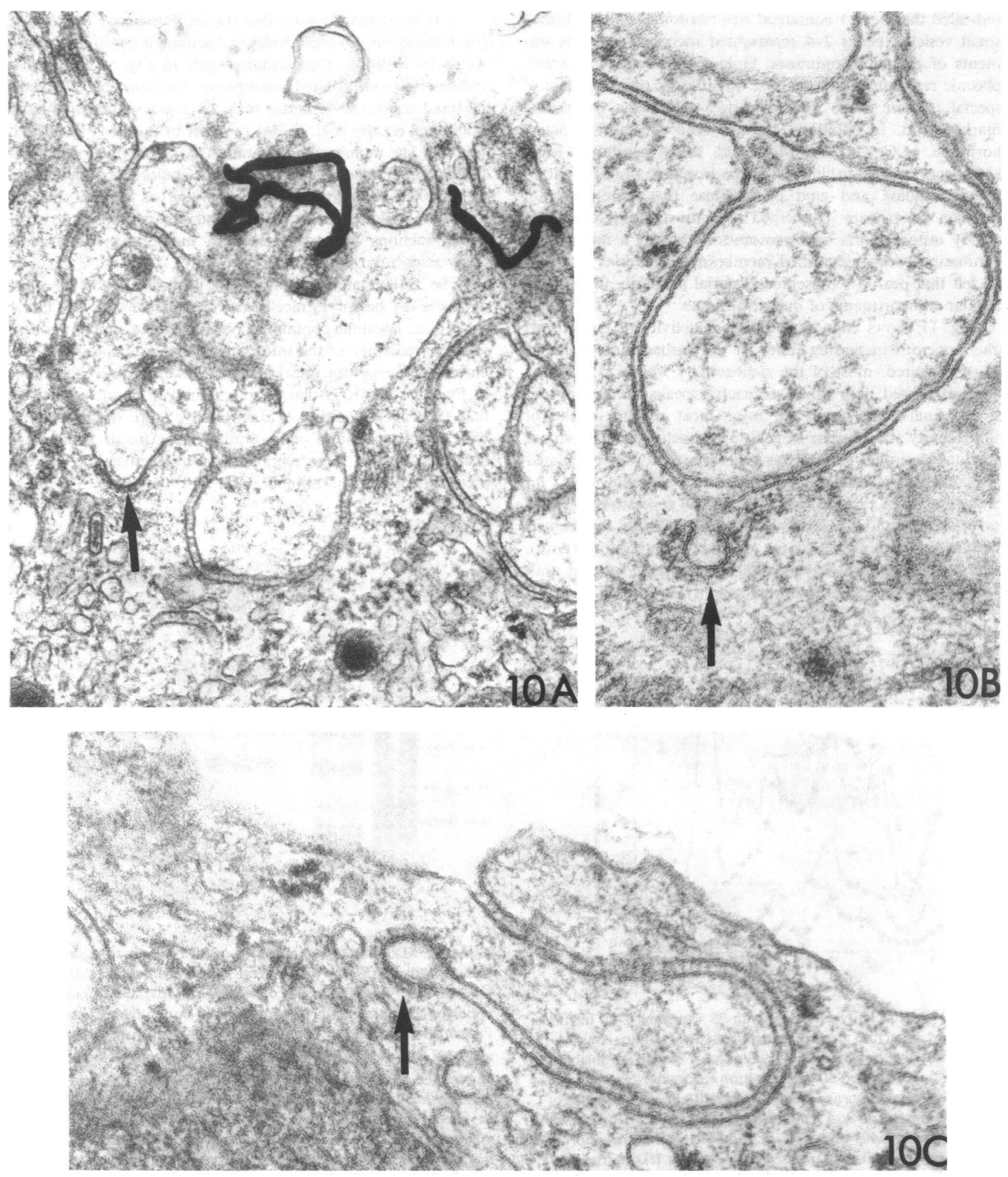

Figure 10. Autoradiograms from luteal cell surface of tissue perfused as in Fig. 6. Micrographs $10 A(\times 70,000), 10 B$, and $10 C$ $(\times 116,000)$ show that coated pits are occasionally associated with the inverted surface of the microvillus-usually at their base (arrows); these sites are not generally labeled, even when exposed grains appear in the same microvillus cavities $(10 \mathrm{~A})$. See also Fig. 7. 
indicated that peak 1 contained free ribosomes and associated small vesicles; peaks 2-4 represented increasingly larger segments of plasma membranes, Golgi membranes, and endoplasmic reticulum. The heaviest membranes (peak 5) were of special interest, since they were free of plasma membrane markers and, in addition, did not bind the surface active hormone, hCG. On the other hand, these membranes were highly enriched for succinic-INT-dehydrogenase (mitochondrial) $\beta$-glucuronidase and acid phosphatase (lysosome) activity. Electron microscopy confirmed that the fraction contained mostly mitochondria and lysosomes with only a minor contamination with unidentified membranous material. As such, we felt that peak 5 represented material primarily from intracellular compartments of the luteal tissue.

Fig. 11 shows changes in the radioactivity of the various fractions with increasing time. At the earliest time point (5 min) measured, most of the radioactivity was in peak 3 . As time progressed, four other radioactive peaks developed, and at the final time point $(50 \mathrm{~min})$ most of the uptake of radioactivity was present in peak 5 (mitochondrial/lysosomal fraction). A similar pattern was seen if the data were calculated as percentage of total radioactivity (data not shown). At an early time point, peak 3 (fractions $14-19$ ) represented $31 \%$ of the total radioactivity and peak 5 (fractions 30-36) represented $3.8 \%$ of the total radioactivity. At a late time point $(50 \mathrm{~min})$, peak 3 contained only $21 \%$ of total radioactivity, whereas peak 5 now contains $22 \%$ of total radioactivity.

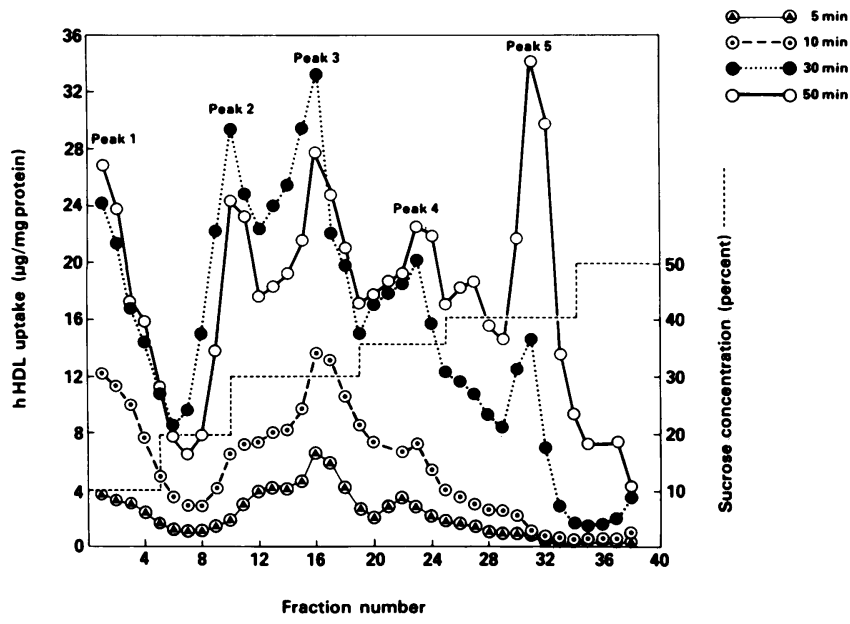

Figure 11. Radioactivity associated with 38 sequential $1-\mathrm{ml}$ fractions obtained from sucrose gradient centrifugations of ovaries continuously perfused with ${ }^{125} \mathrm{I}-\mathrm{h}-\mathrm{HDL}(1 \mu \mathrm{C} / \mathrm{ml}$ plus $200 \mu \mathrm{g} / \mathrm{ml}$ unlabeled HDL) for 5, 10, 30, and $50 \mathrm{~min}$. Electron microscopy and enzyme analyses indicate that peaks 2 and 3 represent enriched fractions of plasma membrane; peak 4 represents plasma membrane mixed with microsomes and Golgi structures; peak 5 represents mitochondria and lysosomes. Uptake is expressed as microgram HDL protein bound $\left({ }^{125} \mathrm{I}-\mathrm{h}-\mathrm{HDL}\right.$ plus unlabeled HDL).
It is important to note that the large majority $(\sim 90 \%)$ of the radioactivity in these isolated fractions is precipitable with TCA. In addition, representative gels in Fig. 12 show that radioactivity in isolated membrane fractions of ${ }^{125} \mathrm{I}-\mathrm{HDL}$ perfused ovaries co-migrates with the major radioactive band (identified as apo A-I, 27,000 mol wt) in purified ${ }^{125} \mathrm{I}$-labeled $\mathrm{h}$-HDL. The membrane preparation also contained a radiolabeled protein band in the approximate molecular weight range of 66,000 . This protein was identified as human plasma albumin, which exists as a lightly labeled contaminant in $\mathrm{h}$ HDL fractions but associates with membrane components (fatty acids?) during isolation procedures.

The time-related accumulation of radioactivity in what appeared to be an intracellular compartment of the luteal tissue (i.e., fractions containing lysosomes and mitochondria), was contradictory to the information that was obtained from autoradiograms of the intact tissue. It was no surprise, therefore, to find in EM-ARGs that were prepared from such fractions that the exposed grains of fraction five were not associated with the mitochondria or lysosomes of the fraction, but were distinctly labeling large membranous fragments that had coprecipitated with the mitochondria and lysosomes. The mor-

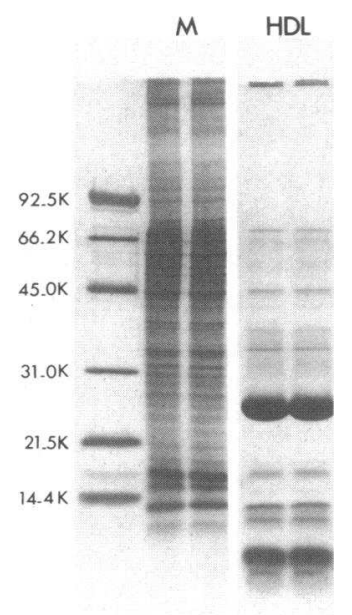

(A)

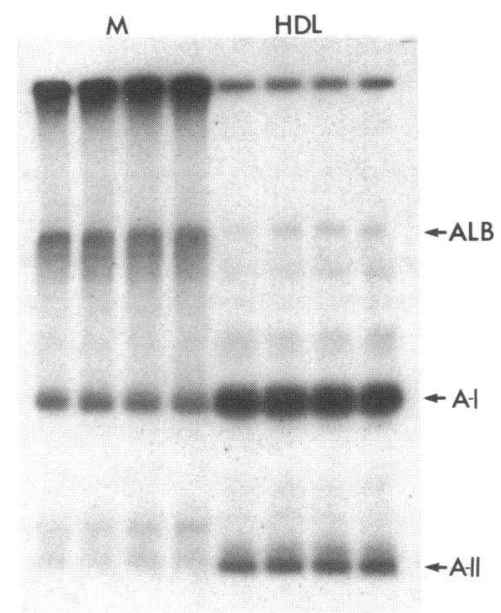

(B)
Figure 12. SDS polyacrylamide (12\%) gels showing protein staining and autoradiograms of a post-nuclear membrane fraction (M) obtained from ${ }^{125} \mathrm{I}-\mathrm{h}-\mathrm{HDL}$ perfused luteinized ovaries and from the radiolabeled human HDL preparation used during the perfusion. Protein staining patterns of molecular weight standards, membranes, and HDL are shown in (1). Autoradiograms of the same membrane and labeled HDL preparations are shown in 0 . The positions of apo A-I, apo A-II, and albumin (ALB) are indicated. Protein standards are phosphorylase B (92.5 K equals $92,500 \mathrm{~mol} \mathrm{wt})$, BSA $(66,200$ $\mathrm{mol} \mathrm{wt})$, ovalbumin $(45,000 \mathrm{~mol} \mathrm{wt})$, carbonic anhydrase $(31,000$ mol wt), soybean trypsin inhibitor $(21,500 \mathrm{~mol} \mathrm{wt})$, and lysozyme (14,400 mol wt). 
phological details of these fragments were more faithfully preserved in the "special mitochondrial fractions" that are illustrated in Fig. 13. In large part, the exposed grains of these fractions were associated with membranous structures that resembled the inverted MV that are illustrated in Figs. 7-10. These fragments are sometimes empty but usually have a loose fibrillar interior similar to the microvillus cavities seen in the intact tissue: more certain identification came from the fact that many of these structures still retained the double membranes with fibrillar connections (see arrows) that are seen so clearly in Figs. 8-10.

By taking advantage of the characteristic appearance of these membrane fragments, we were able to quantitatively assess their content in the special mitochondrial fraction and their degree of labeling with radioactive HDL (Table III). Although these structures (limited by striated double plasma membranes) represented no more than $2 \%$ of the organelles of the fraction, they were heavily labeled: i.e., $\sim 25 \%$ of the exposed grains were associated with these unique structuresa 13-fold enrichment. Table III also shows that the relative labeling of single membraned vesicles (primarily plasma membrane fragments) was greater than unity, but neither mitochondria or lysosomes (included in the category labeled 'other') were labeled beyond the relative content of these structures within the fraction.

\section{Discussion}

The results from this study confirm the data from Paavola and Strauss III (2) that in the superovulated rat model, luteal cells bind both human and rat HDL with great specificity. Our findings indicate, however, that $\sim 90 \%$ of the protein moiety of the HDL remains with the plasma membrane of the cell, and is not internalized. Evidence from autoradiographs suggests further that with time, after perfusion with HDL, an increasing proportion of the plasma membrane-bound protein is associated with inverted MV, which are embedded within the cytoplasm, and, as such, is in intimate association with intracellular structures of the cell. We believe these embedded MV are sheared from the rest of the cell surface during homogenization of the ovary and, during sucrose gradient separation of cell components, co-precipitate with the heaviest of the cell organelles, mitochondria and lysosomes. Thus, as more labeled protein moves into the invaginated microvillus cavities of the cells with increasing time of perfusion, more of these regions are labeled, and this increases the radioactivity associated with the mitochondria/lysosomal fraction, though little radioactivity is actually associated with the mitochondria or lysosomes themselves.

The functional connotations of this finding are not yet clear. On the one hand, these data provide morphological

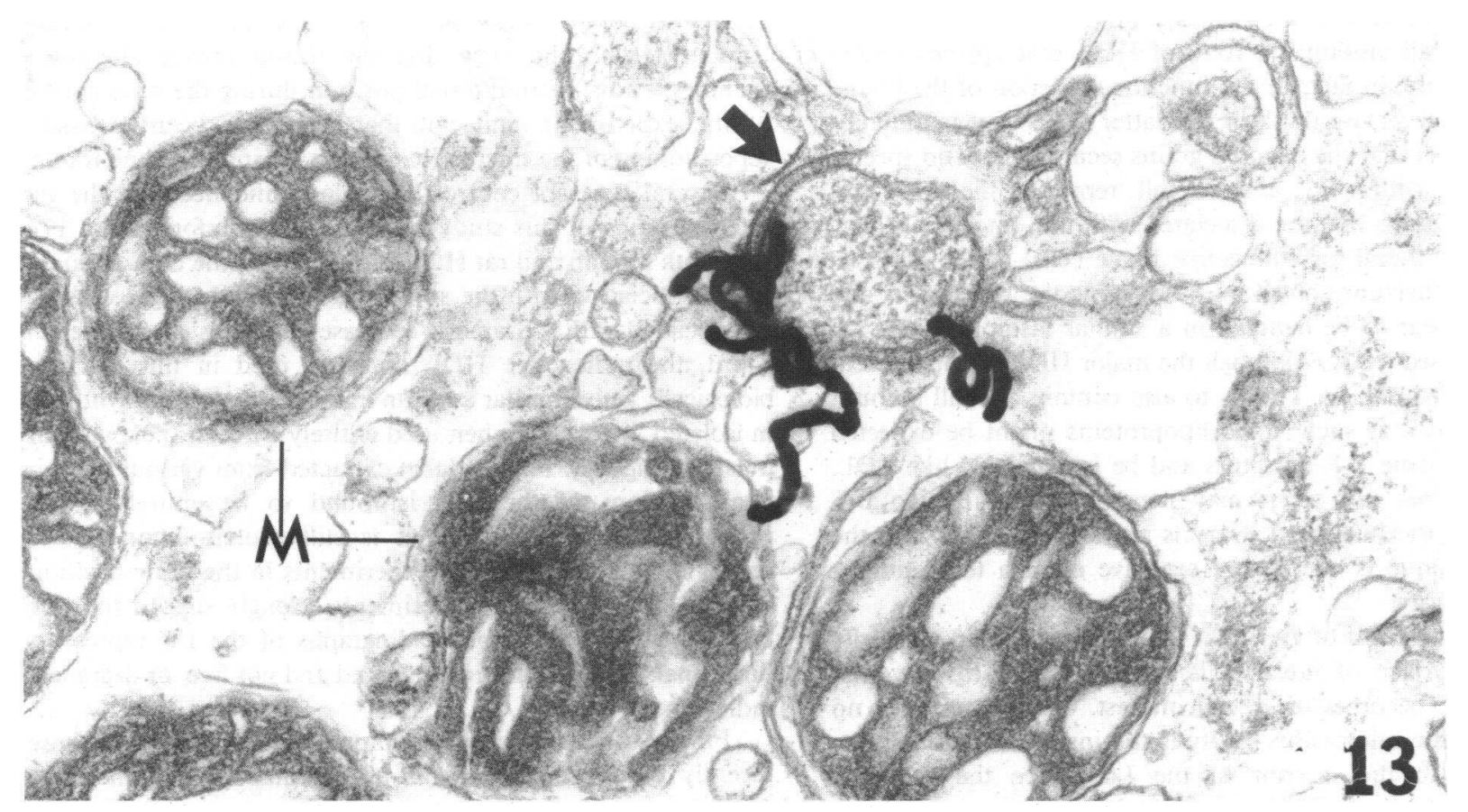

Figure 13. Autoradiogram of "special mitochondrial" fraction from ovaries perfused for $50 \mathrm{~min}$ with ${ }^{125} \mathrm{I}-\mathrm{r}-\mathrm{HDL}(45 \mu \mathrm{C} / \mathrm{ml})$. Exposed grains are associated with structures (vacuoles bounded by double plasma membranes with characteristic striations, see arrow) that strongly resemble the microvillus cavities seen in intact luteal cells (see Figs. 6-10). M, mitochondria; recognizable lysosomes are not present in this figure. (Exposure time equals 8 wk.) 
Table III. Association of Radioactivity with Structures of Special Mitochondrial Fraction

\begin{tabular}{llll}
\hline & $\begin{array}{l}\text { A } \\
\text { Volume } \\
\text { density } \\
\text { of structures }\end{array}$ & $\begin{array}{l}\text { B } \\
\text { Number of } \\
\text { exposed } \\
\text { grains }\end{array}$ & $\begin{array}{l}\text { Relative } \\
\text { specific } \\
\text { activity (B/A) }\end{array}$ \\
\hline & \% Total & \% Total & \\
Double-membraned vacuolesł & 2 & 25 & 12.50 \\
Single-membraned vesicles§ & 37 & 54 & 1.50 \\
Mitochondria & 37 & 20 & 0.54 \\
Other (including lysosomes) & 24 & $<1$ & 0.03
\end{tabular}

* Mitochondrial-enriched fractions were obtained from ovaries of rats perfused with ${ }^{125} \mathrm{I}-\mathrm{h}-\mathrm{HDL}(45 \mu \mathrm{C} / \mathrm{ml})$ plus $200 \mu \mathrm{g}$ unlabeled $\mathrm{HDL} / \mathrm{ml}$ for $50 \mathrm{~min}$.

‡ Vacuoles of striated (plasma) membranes as shown in Fig. 13. $\S$ Single-membraned vesicles probably include segments of plasma membranes and fragments of various intracellular membranes.

evidence for the findings of Rothblat et al. (17) and Jansen et al. (18), who suggest that HDL bind to cell surfaces and release their cholesterol content into cells without the protein moiety of the HDL that is being internalized. On the other hand, it is possible that LC progesterone production could be supported by only a fraction of the ligand that is actually bound, and that the small amount $(\sim 10 \%)$ of HDL that appears within the cells could, in fact, be the functional portion of the bound ligand. However, we think of this latter possibility as unlikely, given the fact that the exposed grains seem to show no specific distribution within LC, and, overall, represent the same proportion of grains that are associated with non-luteal cells (e.g., endothelial, thecal, or connective tissue cells) of the perfused tissue. Another unresolved issue concerns the fact that $r$ - and h-HDL appear to be handled in a similar fashion by the LC of the perfused ovary. Although the major HDL apolipoprotein is apo A-I, r-HDL are known to also contain a small amount of apo E (19): as such, these lipoproteins might be expected to bind to tissue B-E receptors and be internalized like LDL. That this does not occur may mean that the in vivo B-E pathway in the luteinized ovary is not significant, or that the ARG technique is simply not sensitive enough to identify a minor pathway.

Given the point of view that HDL are associated primarily with the surface of luteal cells, the nature of the inverted surface MV becomes of special interest. Clearly, we have no proof that the microvillus cavity is the instrument of delivery of ligands to the interior of the LC (since the observed movement of the HDL label could be due to an unrelated cycling phenomenon of the membranes). However, if HDL protein does not by itself enter the cells, it is necessary to consider how and where HDL-cholesterol may be released. Three possibilities come to mind: $(a)$ perhaps free cholesterol diffuses through the microvillus wall and its cross-bridges; $(b)$ perhaps the membrane of the bulbous base of the inverted microvillus structure segregates into cholesterol-rich regions that subsequently detach from the main membrane structure and carry cholesterol into the cells; or $(c)$ perhaps one of several types of preexisting intracellular vesicular structures (e.g., coated vesicles or smooth- or rough-surfaced endoplasmic reticulum vesicles) temporarily join the microvillus membrane at specified sites and carry off portions of cholesterol-enriched membrane. Obviously, these issues must be probed by more specific techniques before any conclusions can be drawn.

It is important to realize that the inverted MV described here represent more than a simple invagination of the cell surface. In the present situation, a fingerlike portion of one cell has turned in on its own cytoplasm and become embedded, or has become embedded in a neighboring cell, in both cases producing double-membraned structures. These embeddedmicrovillus regions give the appearance of permanence, since they show specialized intermembrane links between the double sets of plasma membranes and they withstand membrane isolation procedures as seen in Fig. 13. The occasional presence of coated pits at the base of the microvillus-like cavities implies that the double-membrane structures were in position long enough for coated regions to form on their cytoplasmic surface-or else the previously coated regions of the plasma membrane actually directed the positioning of the MV to include the coated areas. These various structural findings are consistent with the view that the ligand moves along the membrane to a more internal position during the time course of the experiment, and not that there has been extensive repositioning of the microvillus fingers during this time frame.

Several types of controls provide confidence that the radioautographs of this study present reliable information. For one, both human and rat HDL provide the same data. Second, HDL association with the surface of the LC during perfusion is associated with a dramatic increase in progesterone release. Third, the radioactive HDL that was used in this study is biologically active insofar as it can initiate progesterone synthesis in isolated luteal cells when used entirely by itself (i.e., without unlabeled ligand). Finally, label extracted from various subcellular fractions of the cells is found to be entirely TCAprecipitable (indicating that it is still protein bound), and travels in gel electrophoresis experiments in the same position as HDL apo A-I. These experiments strongly suggest that the label visualized in the autoradiographs of the LC represents functional, intact HDL-protein ligand and not free, or degraded, radioactivity.

Finally, it is necessary to compare these results with those recently published by Paavola and Strauss III (2). In many ways the results are similar: i.e., in both studies, the luteinized ovary proved to have a striking avidity for intravascular HDL, which identifies it as a superior model for the study of in vivobound ligand. In both studies, HDL was bound almost exclusively to the LC of the tissue, which demonstrated good 
specificity of the model. In both cases, the perfused ligand could initiate progesterone synthesis. However, Paavola and Strauss III (2) believe that a major proportion of the luteal cell-bound HDL enters the cell, whereas evidence from the current study would dispute that. We believe these differences can be explained by variations in experimental technique. First, the level of ligand radioactivity was so relatively low in the Paavola-Strauss study that it was necessary to use animals that were treated with the cholesterol-lowering agent 4-aminopyrazole [3,4]- $d$-pyrimidine (4-APP) before autoradiographs at the EM level were possible. It may be that cells of 4-APPtreated luteinized rats use HDL somewhat differently than rats not treated with this agent. Also, the low radioactivity that was achieved may not have permitted a distinction to be made between specific and nonspecific grains. More importantly, the total concentration of HDL (radiolabeled plus unlabeled) given to rats in the Paavola-Strauss study was far below the saturation level of the tissue for HDL, even in rats not treated with 4APP (see Fig. $2 \mathrm{~A}$ ), and it is possible that in the nonsaturated state, a relatively high proportion of the introduced label would be metabolized nonspecifically (and internalized). But, perhaps most important is the fact that in the pulse-chase type experiments carried out by Paavola and Strauss III (2), the number of bound HDL on the surface of the cell greatly diminishes with time, thus making any comparison of the percentage of exposed grains from inside to outside the cell impossible to interpret. In initial pulse-chase type experiments from this laboratory, a similar situation occurred that led us to the current experimental design, where HDL uptake was evaluated exclusively under steady state conditions.

In summary, the current experiments provide morphological evidence that in the in situ perfused luteinized ovary of the rat, the intact HDL particle is not internalized during initiation of steroidogenesis. We show that the protein moiety of the particle remains associated with the plasma membrane of the cell at all times. Furthermore, we speculate that cholesterol may be transferred from the HDL particle to intracellular vesicles from some specialized region of the plasma membrane that makes close contact with the interior of the cell through inverted fingers of microvilli. More direct evidence in support of this theory is currently being sought in our laboratory.

\section{Acknowledgments}

The authors wish to acknowledge the help of Dr. Carl Mondon in setting up the perfusion procedures and Shiaw-Fen Hwang and Friederike Freymark for excellent technical assistance in this study.

\section{References}

1. Gwynne, J. T., and J. F. Strauss III. 1982. The role of lipoproteins in steroidogenesis and cholesterol metabolism in steroidogenic glands. Endocrine Reviews. 3:299-329.
2. Paavola, L. G., and J. F. Strauss III. 1983. Uptake of lipoproteins by in situ perfused rat ovaries: identification of binding sites for high density lipoproteins. J. Cell Biol. 97:593-606.

3. Edelstein, C., C. T. Lim, and A. M. Scanu. 1972. On the subunit structure of the protein of human serum high density lipoprotein. I. A study of its major polypeptide component (sephadex, fraction 3). $J$. Biol. Chem. 247:5842-5849.

4. Azhar, S., and E. Reaven. 1982. Effect of antimicrotubule agents on microtubules and steroidogenesis in luteal cells. Am. J. Physiol. 243:E380-E386.

5. Tan, C. H., and J. Robinson. 1977. The superovulated rat: its use as a model in studies on the acute steroidogenic effects to luteinizing hormone. Endocrinology. 101:396-402.

6. Williams, M. A. 1977. Autoradiography and immunocytochemistry. In Practical Methods in Electron Microscopy. A. M. Glauert, editor. North Holland Publications, Amsterdam. 79-155.

7. Salpeter, M. M., and L. Bachmann. 1972. Autoradiography. In Principles and Techniques of Electron Microscopy. M. A. Hayat, editor. Van Nostrand Reinhold Co., New York. 221-278.

8. Azhar, S., S.-F. Hwang, and E. P. Reaven. 1983. Effect of antimicrotubule agents on terminal glycosyltransferases and other enzymes associated with rat liver subcellular fractions. Biochem. J. 212:721-731.

9. Azhar, S., Y.-D. I. Chen, and G. M. Reaven. 1983. Stimulation of lipoprotein receptors and role of lipoprotein and cellular cholesterol during gonadotropin-induced desensitization of steroidogenic response in luteinized rat ovary. J. Biol. Chem. 258:3735-3740.

10. Reaven, E., and S. Azhar. 1981. Effect of various hepatic membrane fractions on microtubule assembly with special emphasis on the role of membrane phospholipids. J. Cell Biol. 89:300-308.

11. Weibel, E. R. 1973. Stereological techniques for electron microscopy morphometry. In Principles and Techniques of Electron Microscopy. M. A. Hayat, editor. Van Nostrand Reinhold Co., New York. 237-291.

12. Reaven, E. P., and G. M. Reaven. 1980. Evidence that microtubules play a permissive role in hepatocyte very low density lipoprotein secretion. J. Cell Biol. 84:28-39.

13. McFarlane, A. S. 1958. Efficient trace-labeling of proteins with iodine. Nature (Lond.). 182:53.

14. Chen, Y.-D. I., F. B. Kraemer, and G. M. Reaven. 1980. Identification of specific high density lipoprotein-binding sites in rat testis and regulation of binding by human chorionic gonadotropin. $J$. Biol. Chem. 255:9162-9167.

15. Abraham, G. E., R. Garza, and F. S. Manlimos. 1977. Radioimmunoassay of steroids. In Handbook of Radioimmunoassay. G. E. Abraham, editor. Marcel Dekker, Inc., New York. 591-656.

16. Laemmli, U. K. 1970. Cleavage of structural proteins during the assembly of head of bacteriophage $T_{4}$. Nature (Lond.). 227:680685 .

17. Rothblat, G. H., L. Y. Arbogast, and E. K. Ray. 1978. Stimulation of esterified cholesterol accumulation in tissue culture cells exposed to high density lipoproteins enriched in free cholesterol. $J$. Lipid Res. 19:350-358.

18. Jansen, H., and W. J. DeGreef. 1981. Heparin-releasable lipase activity of rat adrenals, ovaries and testes. Biochem. J. 196:739-745.

19. Chapman, M. J. 1980. Animal lipoproteins: chemistry, structure and comparative aspects. J. Lipid Res. 21:789-853. 